BNL-108136-2015-JA

\title{
Purification of CdZnTe by Electromigration
}

\author{
KiHyun Kim
}

Submitted to the Journal of Applied Physics

April 2015

\author{
Nonproliferation and National Security Department \\ Brookhaven National Laboratory \\ P.O. Box 5000 \\ Upton, New York 11973 \\ www.bnl.gov
}

\section{U.S. Department of Energy \\ Office of Non-proliferation and Verification \\ Research \& Dev (NA-22)}

\begin{abstract}
Notice: This manuscript has been authored by employees of Brookhaven Science Associates, LLC under Contract No. DE-SC0012704 with the U.S. Department of Energy. The publisher by accepting the manuscript for publication acknowledges that the United States Government retains a non-exclusive, paid-up, irrevocable, world-wide license to publish or reproduce the published form of this manuscript, or allow others to do so, for United States Government purposes.
\end{abstract}




\section{DISCLAIMER}

This report was prepared as an account of work sponsored by an agency of the United States Government. Neither the United States Government nor any agency thereof, nor any of their employees, nor any of their contractors, subcontractors, or their employees, makes any warranty, express or implied, or assumes any legal liability or responsibility for the accuracy, completeness, or any third party's use or the results of such use of any information, apparatus, product, or process disclosed, or represents that its use would not infringe privately owned rights. Reference herein to any specific commercial product, process, or service by trade name, trademark, manufacturer, or otherwise, does not necessarily constitute or imply its endorsement, recommendation, or favoring by the United States Government or any agency thereof or its contractors or subcontractors. The views and opinions of authors expressed herein do not necessarily state or reflect those of the United States Government or any agency thereof. 


\section{Purification of CdZnTe by Electromigration.}

K. Kim, ${ }^{1, a}$ Sangsu Kim, ${ }^{2}$ J. Hong, ${ }^{2}$ J. Lee, ${ }^{3}$ T. Hong, ${ }^{3}$ A. E. Bolotnikov, ${ }^{4}$ G .S. Camarda, ${ }^{4}$ and R. B. James ${ }^{4}$

${ }^{1)}$ Dept. of Radiologic Science, Korea University, Seoul, 136-703, Republic of Korea

2) Dept. of Applied Physics, Korea University, Sejong, 339-700, Republic of Korea

${ }^{3)}$ AbyzR Corporation, Gyeonggi-do, 445-811, Republic of Korea

${ }^{4)}$ Brookhaven National Laboratory, Upton, New York 11973 USA

(Dated: 12 October 2014)

Electro-migration of ionized/electrically active impurities in CdZnTe (CZT) was successfully demonstrated at elevated temperature with an electric field of $20 \mathrm{~V} / \mathrm{mm}$. Copper, which exists in negatively charged states, electro-migrated at a speed of $15 \mu \mathrm{m} / \mathrm{h}$ in an electric field of $20 \mathrm{~V} / \mathrm{mm}$. A notable variation in impurity concentration along the growth direction with the segregation tendency of the impurities was observed in an electromigrated CZT boule. Especially, both Ga and Fe, which exist in positively charged states, exhibited the opposite distribution to that of their segregation tendency in $\mathrm{Cd}(\mathrm{Zn}) \mathrm{Te}$. A CZT detector fabricated from the middle portion of the electro-migrated CZT boule showed an improved mobility-lifetime product of $0.91 \times 10^{-2} \mathrm{~cm}^{2} / \mathrm{V}$, compared with that of $1.4 \times 10^{-3} \mathrm{~cm}^{2} / \mathrm{V}$, observed in an as-grown (non-electro-migrated) CZT detector. The best radiation detector material would have the minimum concentration of deep traps required for compensation and shallow traps.

\section{INTRODUCTION}

Advances in material purification and crystal growth technology have enabled the use of CdZnTe (CZT) detectors in homeland security and medical applications. The best mobility-lifetime product reported in commercial spectrometer-grade CZT is of the order of $10^{-2} \mathrm{~cm}^{2} / \mathrm{V}$ and their carrier mobility is between 500 and $1000 \mathrm{~cm}^{2} / \mathrm{Vs}$. Conventional CZT detectors, which have mobility-lifetime products of $10^{-3} \sim 10^{-4} \mathrm{~cm}_{2} / \mathrm{V}$, also have similar values of mobility. This means that the prolongation of carrier lifetime is a crucial factor for achieving a high mobility-lifetime product in CZT detectors. Further understanding of the carrier trapping/de-trapping caused by ionized impurities is critical for enhancing the electrical properties of CZT, especially the carrier mobility-lifetime product. The trapping and de-trapping of charge carriers strongly depend on both the trap level in the bandgap and the carrier concentration. For example, a trap located deeper than $0.3 \mathrm{eV}$ from the band edge with a concentration of $10^{13} \mathrm{~cm}^{-3}$ always acts as a charge recombination center instead of a charge-trapping center.

In our previous research, we successfully demonstrated the electro-migration of specific impurities in $\mathrm{TlBr}$ under strong electric fields at room temperature and identified their ionic states [1]. Unlike $\mathrm{TlBr}$, which exhibits levels of ionic conductivity, CZT has 
strong covalent bonding, so we cannot observe any electro-migration in room temperature. However, electro-migration has a temperature dependence of $\sim \exp (-\mathrm{Ea} / \mathrm{kT})$ so electro-migration experiments at elevated temperatures might induce a drift of ionic and charged impurities under an electric field. The impurity analysis for an electromigrated CZT boule will envisage the electronic states of the ionized impurities. In addition, pulse height spectra measurements for a CZT detector fabricated from electropurified CZT boule might give qualitative data on the effects of impurities on the detector's performance.

\section{EXPERIMENT}

For the electro-migration experiment, CZT ingots were grown with $7 \mathrm{~N}$ purity of elemental Cd, Zn, Te, 2 ppm of indium, and $2 \%$ of excess Te by the vertical Bridgman method. The as-grown material showed resistivity of $\sim 10^{10} \Omega \mathrm{cm}$ and a mobility-lifetime product of $1.4 \times 10^{-3} \mathrm{~cm}^{2} / \mathrm{V}$. We measured the temperature dependence of the leakage current in order to determine the proper temperature for the electro-migration experiment, as shown in Fig. 1, using a specially designed quartz ampoule, shown in Fig. 2. The leakage current of CZT was monitored in real time with the temperature, and the temperature for the electro-migration experiment was set at $220^{\circ} \mathrm{C}$.

The CZT electro-migration experiments were conducted in two different ways. The detection limit of the micro X-ray fluorescence ( $\mu$-XRF) system used at Brookhaven National Laboratory was about $1 \mathrm{ppm}$ and the overall impurity concentrations in the $7 \mathrm{~N}$ material was just $1 \sim 2$-ppm; therefore, it was not easy to visualize the electro-migration of specific impurities in high-purity materials. In the first experiment, we co-deposited a 3000-A Cu layer and a 2000-A Au layer by sputtering on the one side and only Au on the other side by the electro-less method of a $10 \times 10 \times 3-\mathrm{mm}^{3}$ and a $10 \times 10 \times 2-\mathrm{mm}^{3} \mathrm{CZT}$ detector. The two CZT samples were loaded on the specially designed quartz ampoule and sealed in a vacuum of $10^{-6}$ torr. The sealed quartz ampoules were loaded in an isothermal furnace and we applied an electric field of $20 \mathrm{~V} / \mathrm{mm}$ for 7 days. In the second experiment, a CZT boule with 27-mm diameter and 30-mm length was selected to evaluate the electro-migration of impurities at elevated temperature. Carbon has been known to be electrically neutral in CZT so we fabricated both electrodes of the CZT boule using a high-purity graphite paste. Subsequently, we followed a same procedure as in the first experiment. Here, we maintained an electric field of $20 \mathrm{~V} / \mathrm{mm}$ for 60 days to ensure electro-migration. After the 60-day electro-migration, we fabricated a $10 \times 10 \times 2$ $\mathrm{mm}^{3} \mathrm{CZT}$ detector from the middle part of the electro-purified CZT boule and measured the pulse height spectra with an ${ }^{241} \mathrm{Am}$ gamma source to evaluate the effects of electromigration on the CZT detector's performance.

The bias polarity and the growth direction of the ingot were carefully recorded in order to distinguish the impurity distributions caused by segregation and electromigration. The impurity profiling and concentrations were analyzed by the $\mu-\mathrm{XRF}$ and a glow-discharge mass spectroscopy (GDMS) system.

\section{RESULTS AND DISCUSSION}


The impurity concentrations in melt-grown CZT crystals depend on the freezing position, owing to the segregation coefficients of the respective impurities [2]. However, in fewmillimeter-thick samples, the difference in the impurity concentrations is negligible. For the electro-migration, the high leakage current above $200{ }^{\circ} \mathrm{C}$ restricted the application of a high electric field with a source-measure unit to the CZT sample; therefore, we specifically chose $\mathrm{Cu}$ impurities, which are known to be a fast-moving agent in CZT, to prove the electro-migration of impurities at an elevated temperature. In the two CZT samples, the one electrode consisted of $\mathrm{Au} / \mathrm{Cu}$ and the other electrode of $\mathrm{Au}$ only. Negative bias was applied to the $\mathrm{Au} / \mathrm{Cu}$ electrode for the first attempt and positive bias was applied to the $\mathrm{Au} / \mathrm{Cu}$ electrode for the second attempt. The current transients of CZT were monitored throughout the electro-migration experiment.

Fig. 3 shows the $\mathrm{Cu} \mathrm{K}_{\alpha}$ trace in a cross-section of the 3-mm-thick CZT sample when negative bias was applied on the $\mathrm{Au} / \mathrm{Cu}$ electrode and the 2-mm-thick CZT sample with positive bias applied on the $\mathrm{Au} / \mathrm{Cu}$ electrode for one week at $220^{\circ} \mathrm{C}$. Depending on the bias polarity, the $\mathrm{Cu}$ distribution has completely different features. In the case of the negative bias, the distribution of $\mathrm{Cu}$ is fairly uniform in the entire cross-section except the side part, owing to edge effects. However, for the positive bias, the $\mathrm{Cu}$ trace was just detectable below the $\mathrm{Au} / \mathrm{Cu}$ electrode. These results imply that $\mathrm{Cu}$ moved from one side to the other by electro-migration and the electronic states of $\mathrm{Cu}$ were negative. The approximate electro-migration velocity of $\mathrm{Cu}$ was $14 \sim 16 \mu \mathrm{m} / \mathrm{h}$. The diffusion length of $\mathrm{Cu}$ in CZT, measured at $220{ }^{\circ} \mathrm{C}$ for 7 days, was approximately $27 \mu \mathrm{m}$, considering a diffusion coefficient of $\mathrm{D}_{\mathrm{Cu}}=9.9 \times 10^{-11} \mathrm{~cm}^{2} / \mathrm{s}$ [3]. $\mathrm{Cu}$ is the acceptor in CZT so the $\mathrm{Cu}$ atom states become negative. The charged state of $\mathrm{Cu}$ in CZT was also confirmed from the bias polarity dependence. In the case of $\mathrm{Cd}$, Te, and $\mathrm{Zn}$, we cannot observe any critical stoichiometric changes after electro-migration, as shown in Fig. 4.

The large-volume CZT boule, on which a field of $20 \mathrm{~V} / \mathrm{mm}$ was applied for 60 days, was sliced into three sections for the GDMS measurement. During the electromigration experiment, negative bias was applied to the first-to-freeze side. Fig. 5 shows the distributions of the major impurities in the three different sections, that is, the first-tofreeze (1), middle (2), and last-to-freeze (3) sections. The major impurities in the CZT boule were iron (Fe), copper $(\mathrm{Cu})$, sodium $(\mathrm{Na})$, gallium $(\mathrm{Ga})$, indium (In), and carbon (C). Indium and carbon might originate from the compensation doping and the graphite coating of the quartz ampoule, respectively. The distribution of the major impurities is remarkably different depending on the slice position, as shown in Fig. 5. The segregation coefficients of $\mathrm{Ga}$ and $\mathrm{Fe}$ are $\mathrm{k}_{\mathrm{Ga}}=0.13$ and $\mathrm{k}_{\mathrm{Fe}}=0.28$, respectively [2,4]. This indicates that the concentration of Ga and Fe was higher in the first-to-freeze part than in the lastto-freeze part of the as-grown ingot. However, the Ga and Fe distributions are completely opposite after the electro-migration. This means that the electronic states of $\mathrm{Ga}$ and $\mathrm{Fe}$ are negative ionic states so they electro-migrated to the positive-bias side. On the other hand, the $\mathrm{Na}$ and $\mathrm{Cu}$ distributions are consistent with their segregation tendencies of $\mathrm{k}_{\mathrm{Na}}=0.013$ and $\mathrm{k}_{\mathrm{Cu}}=0.2 \sim 0.5[2,4]$. Therefore, we cannot directly determine the electronic states of $\mathrm{Na}$ from the electro-migration itself. Nevertheless, they might exist in the positive state because $\mathrm{Na}$ and $\mathrm{Cu}$ have been known to act as acceptors. Additional experiments with the same CZT boule configuration under the opposite polarity will provide clarifications on this issue. These results imply that electro-migration at elevated 
temperature is an effective way for the material purification of CZT.

The pulse height spectra taken with the CZT detector that was fabricated from the middle portion of the electro-migrated CZT boule are shown in Fig. 6. The electrical resistivity of the electro-migrated CZT detector slightly dropped from $3 \times 10^{10}$ to $9 \times 10^{9}$ $\Omega \mathrm{cm}$. However, its mobility-lifetime product improved from $1.3 \times 10^{-3}$ to $9.1 \times 10^{-3}$ $\mathrm{cm}^{2} / \mathrm{V}$. The GDMS results for the electro-migrated CZT boule clearly showed the variation of the $\mathrm{Ga}, \mathrm{Cu}, \mathrm{Na}$, and Fe impurities depending on the boule position. Especially, the middle portion contained less $\mathrm{Ga}, \mathrm{Cu}$, and $\mathrm{Fe}$ than the first-to-freeze and the last-to-freeze sections. Among those impurities, $\mathrm{Ga}$ and Na have been known to be a shallow donor $\left(E_{C}-0.013 \mathrm{eV}\right)[5]$ and a shallow acceptor $\left(E_{V}+0.058 \mathrm{eV}\right)$, respectively [6], whereas $\mathrm{Cu}$ [7] and $\mathrm{Fe}$ [8,9] are known as a deep acceptor and a deep donor, correspondingly. However, there is still controversy regarding the exact trap levels of the $\mathrm{Cu}$ and Fe impurities. In very recent research, Biglari et al. found that the $\mathrm{E}_{\mathrm{V}}+0.35-\mathrm{eV}$ trap results from the $\mathrm{Cu}_{\mathrm{Cd}}$ acceptor, whereas the $\mathrm{E}_{\mathrm{V}}+0.15-\mathrm{eV}$ level arises from complexes between $\mathrm{Cu}_{\mathrm{Cd}}$ and the non-controlled $\mathrm{Cl}_{T e}$ donor [10]. Similarly, two different trap levels were found for $\mathrm{Fe}$. The $\mathrm{Fe}^{2+/ 3+}\left(\mathrm{Fe}_{\mathrm{Cd}}\right)$ donor level was found to be located at $\mathrm{E}_{\mathrm{C}}$ - 1.40-eV and the other donor $\left(\mathrm{Fe}_{\mathrm{i}}\right)$ level at $\mathrm{E}_{\mathrm{V}}+0.35 \mathrm{eV}$ [8]. According to previous results, $\mathrm{Fe}$ diffusion occurs via $\mathrm{Fe}$ interstitials $\left(\mathrm{Fe}_{\mathrm{i}}\right)$ instead of $\mathrm{Cd}$ vacancies [6]. Additionally, Fe solubility studies exhibited a clear dependence on the stoichiometry of CZT [6]. Therefore, both $\mathrm{Fe}_{\mathrm{Cd}}$ and $\mathrm{Fe}_{\mathrm{i}}$ point defects might be present in a hightemperature-grown CdTe and CZT. Most of the Cd vacancies in the CZT boule were compensated by indium, so $\mathrm{Fe}$ impurities might be present as a $\mathrm{Fe}_{\mathrm{i}}$. If there are uncompensated $\mathrm{Cd}$ vacancies by the In doping, these might be compensated by Fe; consequently, co-doping of $\mathrm{Fe}$ and In contribute in obtaining a fully compensated material, that is, a high-resistivity material. However, too much Fe will produce a $\mathrm{Fe}_{i}$ level at $\mathrm{EV}+0.35 \mathrm{eV}$ and this will increase charge trapping, thus shortening the carrier lifetime. Lee et al. showed that the trap decay time for the electrons and holes as a function of the trap energy for CZT at room temperature, assuming an average trap cross section of $10^{15} \mathrm{~cm}^{2}$. The traps that were deeper than $\sim 200 \mathrm{meV}$, which are also very important for compensation, were the ones that degraded the radiation detection measurement [11]. The CZT detector fabricated from the middle portion of the electromigrated CZT boule contains fewer $\mathrm{Cu}$ and $\mathrm{Fe}$ impurities, so electron-hole pairs generated by incident gamma rays suffer from less charge trapping and therefore have longer carrier lifetimes. Moreover, low concentrations of $\mathrm{Ga}$, which occupies shallow levels in CZT, might increase the carrier mobility owing to the occurrence of less carrier scattering. The best radiation detector material would have the minimum concentration of deep traps required for compensation and shallow traps.

\section{CONCLUSION}

We successfully demonstrated the electro-migration of impurities in CZT at elevated temperature and established the electronic states of a few impurities. The electro-migration speed of the $\mathrm{Cu}$ impurities was measured to be about $15 \mu \mathrm{m} / \mathrm{h}$ in an electric field of $20 \mathrm{~V} / \mathrm{mm}$ at $220{ }^{\circ} \mathrm{C}$. A CZT detector fabricated from electro-purified material exhibited an improved mobility-lifetime product of $0.91 \times 10^{-2} \mathrm{~cm}^{2} / \mathrm{V}$. Fe and $\mathrm{Cu}$, which occupy deep-level defects $(>0.2 \mathrm{eV})$, seem to be the most important factors 
for achieving mobility-lifetime products of the order of $10^{-2} \mathrm{~cm}^{2} / \mathrm{V}$. More experiments with low-purity CZT material are needed to identify the electronic states of other impurities. The electro-migration experiment in CZT at elevated temperature is very important and useful for the improvement of both material purity and detector performance.

\section{ACKNOWLEDGMENT}

This work was supported by a grant from AbyzR Co. and the U.S. Department of Energy Office of Defense Nuclear Nonproliferation Research and Development, DNN R\&D.

\section{REFERENCES}

[1] KiHyun Kim, Eunlim Kim, H. Kim, R. Tappero, A. E. Bolotnikov, G. S. Camarda, A. Hossain, L. Cirignano, and R. B. James, J. Appl. Phys. 114, 133701 (2013).

[2] M. Schieber, T. E. Schlesinger, R. B. James, H. Hermon, H. Yoon, and M. Goorsky, J. Cryst. Growth, 237-249, 2082 (2002).

[3] E. D. Jones, N. M. Stewart, and J. B. Mullin, J. Cryst. Growth 117, 244 (1992).

[4] K. Zanio, J. Electron. Mater. 3, 327 (1974).

[5] M. Joerger, M. Lassch. T. Kunz, M. Fiederle, J. Meinhardt, K. W. Benz, K. Scholz, W. Wendl, and G. Mu 1ler-Vogt, Cryst. Res. Technol. 32, 1103(1997).

[6] O. Panchuk and P. Fochuk, "Doping” in CdTe and Related Compounds; Physics, Defects, Hetero- and Nano-structures, Crystal Growth, Surfaces and Applications, 1st ed. Edited by Robert Triboulet and Paul Siffert, Amsterdam: Elsevier, 2010, pp. 309-362.

[7] G. Chen, I. Miotkowski, and A. K. Ramdas, Phys. Rev. B 85,165210 (2012).

[8] K. Lischka, G. Brunthaler, and W. Jantsch, J. Cryst. Growth 72, 355 (1985).

[9] W. Jantsch and G. Hendorfer, J. Cryst. Growth, 101, 404 (1990).

[10] B. Biglari, M. Samimi, and M. Hage-Ali, Nucl. Instrum. Methods A 283, 249 (1989).

[11] E. Y. Lee, R. B. James, R. W. Olsen, H. Hermon, J. Electron. Mater. 28(6), 766 (1999). 


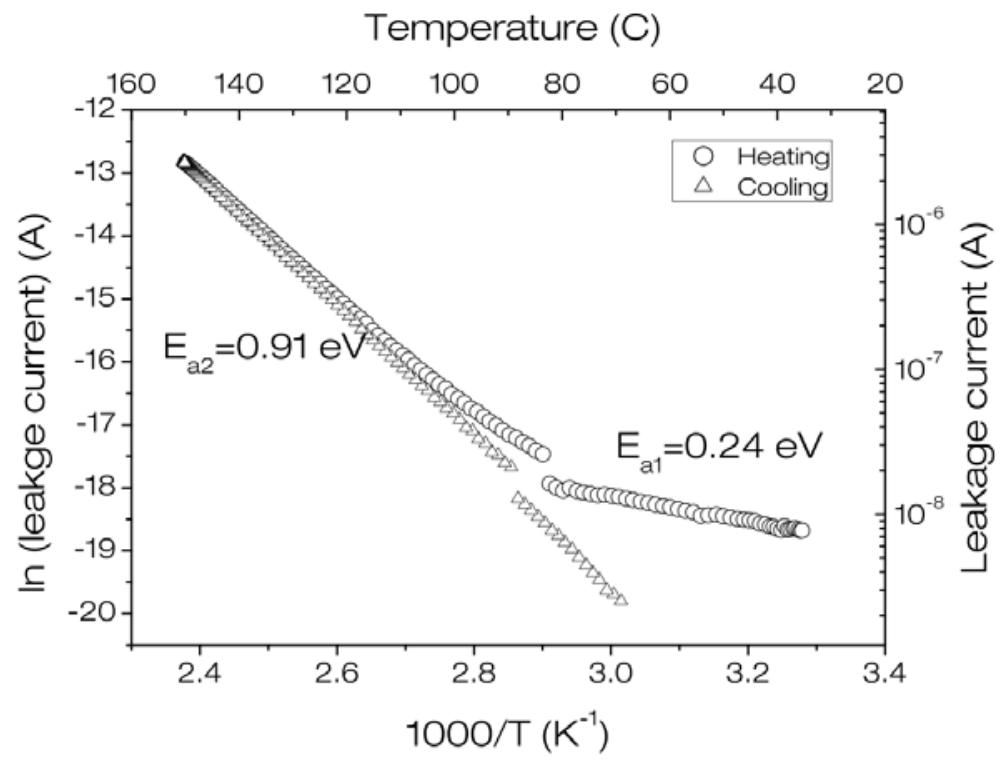

FIG. 1. Temperature dependence of the dark current for a high-resistivity CZT detector. Due to the high dark current at high temperature, an electric field of $20 \mathrm{~V} / \mathrm{mm}$ was adopted for the electro-migration experiment.
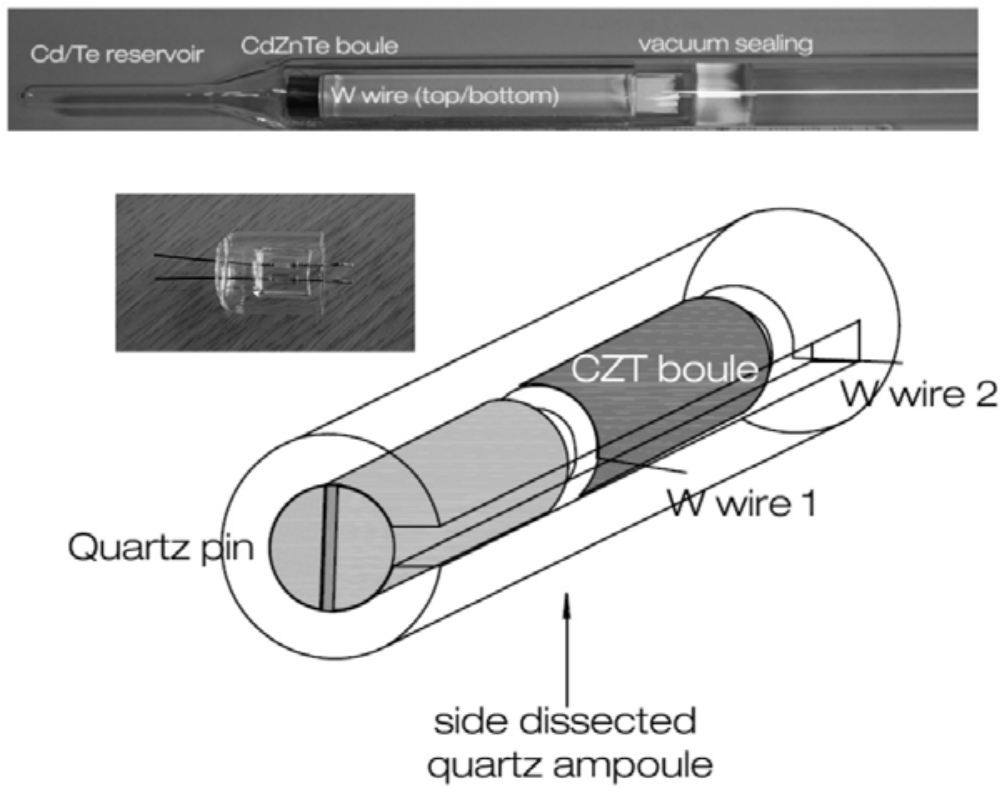
FIG. 2. A photograph of the experimental setup and a schematic of the specially designed CZT boule holder for the electro-migration experiment at elevated temperature.
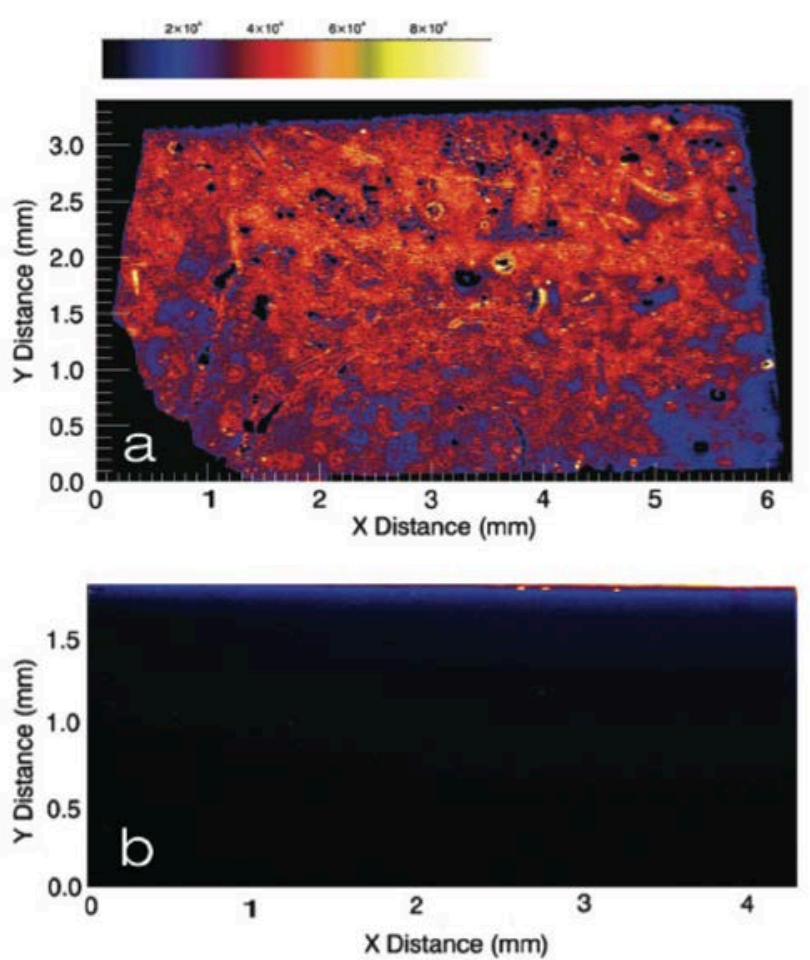

FIG. 3. The $\mathrm{Cu}$ traces measured by $\mu-\mathrm{XRF}$ in vertically cleaved CZT after electromigration in an area of (a) $3 \times 6 \mathrm{~mm}^{2}$ and (b) $2 \times 6 \mathrm{~mm}^{2}$ with a $100-\mu \mathrm{m}$ step. The top of the figure displays the $\mathrm{Au} / \mathrm{Cu}$ electrode (a) with positive bias and (b) with negative bias applied. The spots appearing in the image are surface dents, generated during CZT cleaving. We did not perform any mechanical or chemical polishing to avoid composition changes and external contamination during the polishing process. 

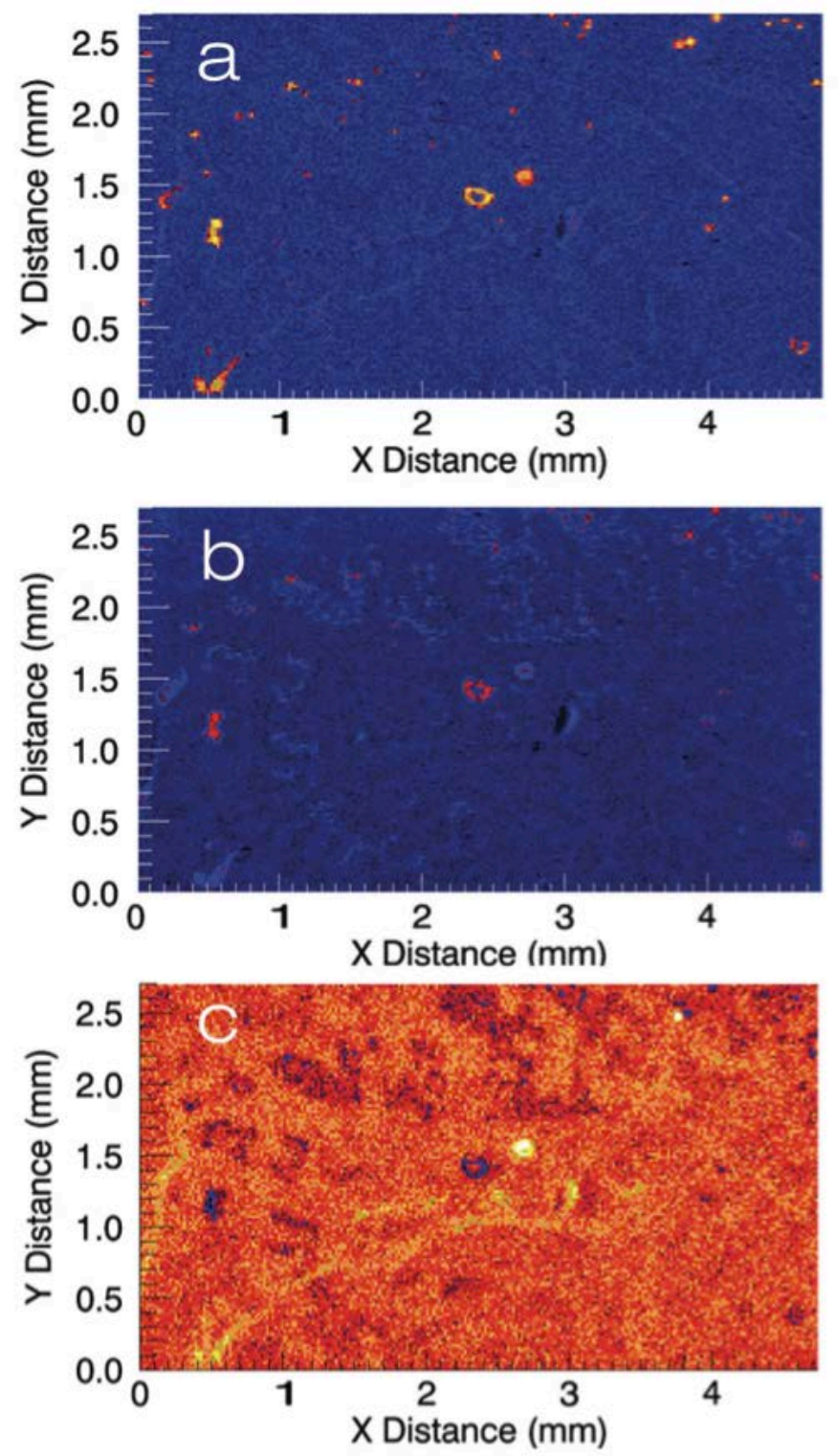

FIG. 4. (a) Cd, (b) Te, and (c) Zn distributions in the electro-migrated 3-mm-thick CZT detectors. The $\mathrm{Cd} L \alpha$, Te $\mathrm{L} \alpha$, and $\mathrm{Zn} \mathrm{K} \alpha$ peaks were used for the two-dimensional mapping of each element. The spots appearing in the image are surface dents, generated during CZT cleaving. We did not observe any severe stoichiometric changes after electro-migration. 

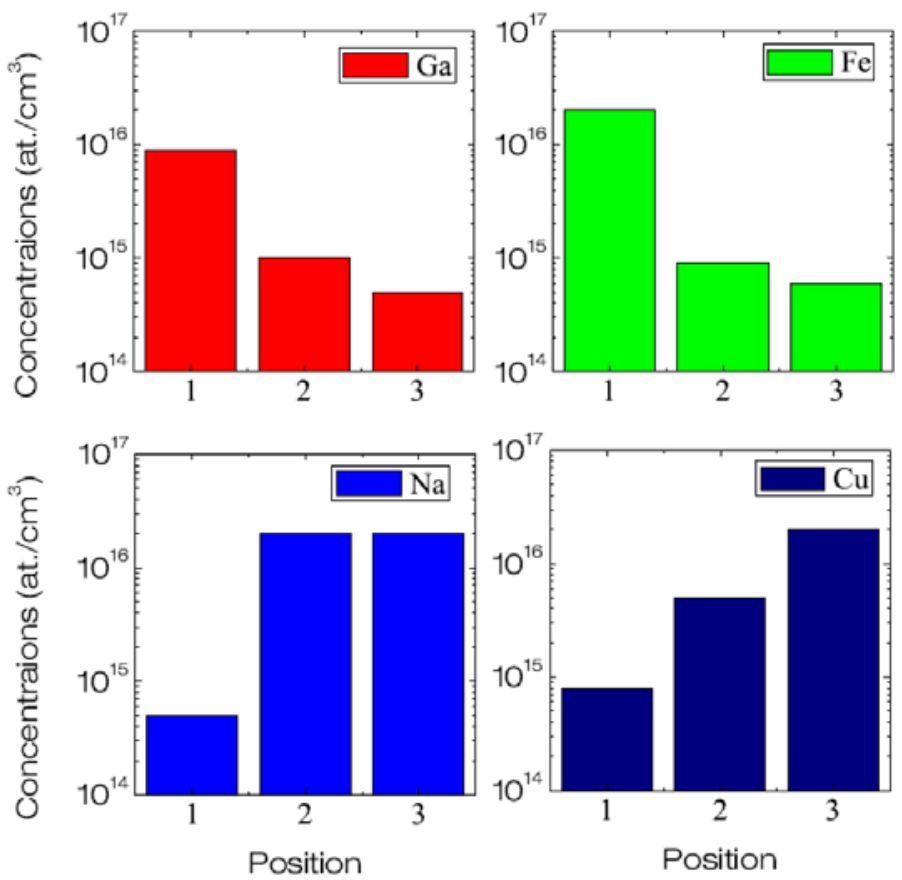

FIG. 5. Impurity concentrations of $\mathrm{Ga}, \mathrm{Cu}, \mathrm{Na}$, and $\mathrm{Cu}$ in the first-to-freeze (1), middle (2), and the last-to-freeze (3) portions of the electro-migrated CZT boule.

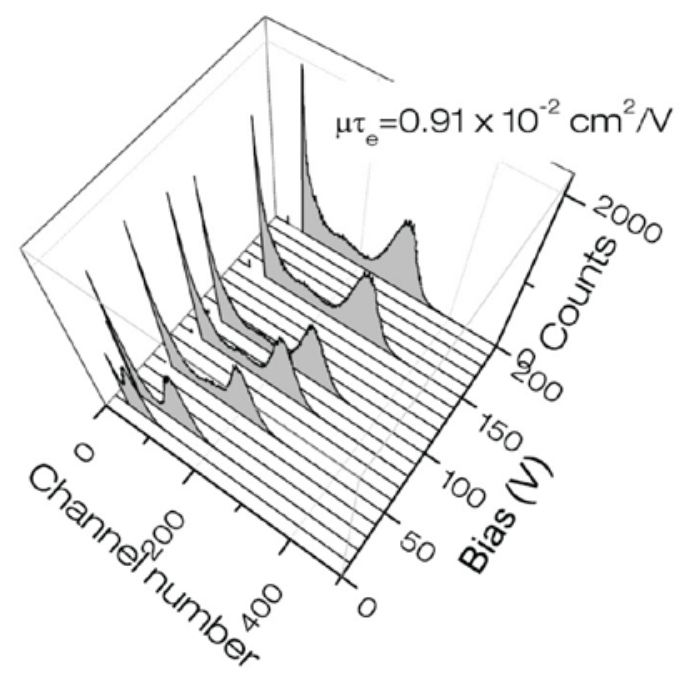

FIG. 6. Pulse height spectra of ${ }^{241} \mathrm{Am}$, taken at room temperature with $10 \times 10 \times 2-\mathrm{mm}^{3}$ CZT detectors fabricated from the middle portion of the electro-migrated CZT boule. The shaping time was set to $6 \mu$ s during the measurement for full charge collection. The 59.5$\mathrm{keV}$ gamma peak was detectable at $10 \mathrm{~V}(5 \mathrm{~V} / \mathrm{mm})$ and saturated at around $50 \mathrm{~V}$. The measurement was conducted with an eV-550 preamplifier, an Ortec 452 amplifier, and an Ortec MCA. 